\title{
SpineCore treatment for idiopathic scoliosis: updates and follow-up results
}

\author{
Christine Coillard, Alin B Circo, Charles-Hilaire Rivard ${ }^{*}$ \\ From 7th International Conference on Conservative Management of Spinal Deformities \\ Montreal, Canada. 20-22 May 2010
}

\section{Introduction}

The purpose of this prospective interventional study was to evaluate and confirm the effectiveness of the Dynamic SpineCor brace for idiopathic scoliosis and to evaluate the stability of the spine after the weaning point.

\section{Material and methods}

From 1993 to 2009, 949 patients were treated by the SpineCor brace. 576 patients had a definite outcome and 373 are still actively being treated. The assessment of brace effectiveness was done following the outcome criteria recommended by the SRS.

\section{Results}

The 576 patients with a definite outcome followed the same pattern of result presented before, $36.3 \%$ corrected their Cobb angle with at least $5^{\circ}$ and $31.3 \%$ had a stabilization of their Cobb angle. Out of all patients with a definite outcome, $16.1 \%$ of patients had surgical recommendation before skeletal maturity and only $9.7 \%$ had a progression of their Cobb angle. Looking at the stability of the curves after the end of the treatment, out of the patients that finished the treatment and had at least 2 years of follow-up, $14.5 \%$ continued their correction even without the brace and it seems that the correction continues more with time because $33.3 \%$ of those patients who had at least 5 years follow-up still corrected their Cobb angle after the weaning of the brace.

\section{Discussion}

Comparing the natural history of the disease and the already published literature these results tend to confirm that it is possible to obtain a correction and a stabilization of the pre-treatment Cobb angle and it seems

Sainte-Justine Hospital, Montreal, Canada

Full list of author information is available at the end of the article possible to maintain and improve the success 2 and even 5 years after the weaning point. This findings suggest that the SpineCor Bracing System can alter the natural history of the AIS and its use in the conservative treatment of this disease is justified.

\section{Conclusion}

In conclusion, the SpineCor brace is effective for the treatment of idiopathic scoliosis. Moreover, the positive outcome appears to be maintained and even improved in the long term.

Published: 10 September 2010

doi:10.1186/1748-7161-5-S1-056

Cite this article as: Coillard et al:: SpineCore treatment for idiopathic scoliosis: updates and follow-up results. Scoliosis 2010 5(Suppl 1):O56.

Submit your next manuscript to BioMed Central and take full advantage of:

- Convenient online submission

- Thorough peer review

- No space constraints or color figure charges

- Immediate publication on acceptance

- Inclusion in PubMed, CAS, Scopus and Google Scholar

- Research which is freely available for redistribution 